\title{
Brain Penetration of Lorlatinib: Cumulative Incidences of CNS and Non-CNS Progression with Lorlatinib in Patients with Previously Treated ALK-Positive Non-Small-Cell Lung Cancer
}

\author{
Todd M. Bauer ${ }^{1}$ - Alice T. Shaw ${ }^{2} \cdot$ Melissa L. Johnson ${ }^{1}$ - Alejandro Navarro ${ }^{3}$. Justin F. Gainor ${ }^{2} \cdot$ Holger Thurm $^{4}$. \\ Yazdi K. Pithavala ${ }^{4}$. Antonello Abbattista ${ }^{5}$. Gerson Peltz ${ }^{6}$. Enriqueta Felip ${ }^{3}$
}

Published online: 14 February 2020

(c) The Author(s) 2020

\begin{abstract} blood-brain barrier.

ClinicalTrials.gov identifier NCT01970865.

Prior presentation Some of the results from these analyses have been presented at the International Association for the Study of Lung Cancer (IASLC) 19th World Conference on Lung Cancer (WCLC), 23-26 September 2018; Toronto, Ontario, Canada; American Society of Clinical Oncology (ASCO) meeting 1-5 June 2018, Chicago, Illinois, USA, and European Medical Society for Oncology (ESMO) meeting, 27 September-1 October 2019, Barcelona, Spain.
\end{abstract}

Background Lorlatinib is a potent, third-generation ALK/ROS1 tyrosine kinase inhibitor (TKI) designed to penetrate the

Objective We report the cumulative incidence of central nervous system (CNS) and non-CNS progression with lorlatinib in patients with ALK-positive non-small-cell lung cancer (NSCLC) previously treated with ALK TKIs.

Patients and methods In an ongoing phase II study (NCT01970865), 198 patients with ALK-positive NSCLC with $\geq 1$ prior ALK TKI were enrolled into expansion cohorts (EXP) based on treatment history. Patients received lorlatinib $100 \mathrm{mg}$ once daily. Patients were analyzed for progressive disease, categorized as CNS or non-CNS progression, by independent central review. Cumulative incidence probabilities were calculated adopting a competing risks approach.

Results Fifty-nine patients received crizotinib as their only prior ALK TKI (EXP2-3A); cumulative incidence rates (CIRs) of CNS and non-CNS progression were both $22 \%$ at 12 months in patients with baseline CNS metastases $(n=37)$, and CIR of non-CNS progression at 12 months was higher versus that for CNS progression in patients without baseline CNS metastases [43\% vs. 9\% $(n=22)$ ]. In patients who received $\geq 1$ prior second-generation ALK TKI [EXP3B-5 $(n=139)$ ], CIR of non-CNS progression at 12 months was higher versus that for CNS progression in patients both with and without baseline CNS metastases (35\% vs. $23 \%(n=94)$ and $55 \%$ vs. $12 \%(n=45)$, respectively).

Conclusions Lorlatinib showed substantial intracranial activity in patients with pretreated ALK-positive NSCLC, with or without baseline CNS metastases, whose disease progressed on crizotinib or second-generation ALK TKIs.

\section{Electronic supplementary material The online version of this} article (https://doi.org/10.1007/s11523-020-00702-4) contains supplementary material, which is available to authorized users.

Todd M. Bauer

tbauer@tnonc.com

1 Sarah Cannon Cancer Research Institute/Tennessee Oncology, PLLC, 250 25th Ave N, Nashville, TN 37203, USA

2 Massachusetts General Hospital, 55 Fruit St, Boston, MA 02114, USA

\section{Key Points}

Lorlatinib is a potent, brain-penetrant, third-generation ALK/ROS1 TKI.

We performed an analysis of CNS and non-CNS progression in patients with pretreated ALK+ NSCLC.

Our results indicate that lorlatinib is active in the treatment and prevention of CNS metastases in patients with ALK+ NSCLC, including those who had progressed on crizotinib or second-generation TKIs.

3 Vall d'Hebron University Hospital, Vall d'Hebron Institute of Oncology (VHIO), Passeig de la Vall d'Hebron, 119-129, 08035 Barcelona, Spain

4 Pfizer Oncology, 10777 Science Center Dr, La Jolla, CA, USA

5 Pfizer Oncology, Via Anna Maria Mozzoni, 12, Milan, Italy

6 Pfizer Oncology, 280 Shennecossett Rd, Groton, CT, USA 


\section{Introduction}

Central nervous system (CNS) metastases are a known complication of anaplastic lymphoma kinase (ALK)-positive non-small-cell lung cancer (NSCLC), occurring in approximately $30 \%$ of patients at the time of diagnosis [1]. In general, the presence of CNS metastases is associated with a poor prognosis, including decreased progression-free survival, and can lead to neurocognitive dysfunction that can negatively affect patient quality of life [2-4].

ALK tyrosine kinase inhibitors (TKIs), including the first-generation TKI crizotinib [5] and second-generation ALK TKIs [6-8], are standard therapies for patients with ALK-positive NSCLC. However, most patients treated with crizotinib will relapse over time because of the development of resistance and poor intracranial disease control [9-11]. The CNS is a common site of progression with crizotinib, likely because of poor CNS penetration as a result of P-glycoprotein-mediated efflux across the blood-brain barrier (BBB) [12]. Despite the development of more potent and BBB-permeable second-generation ALK TKIs, the emergence of resistance and progression of CNS metastases remain clinically significant issues in the management of ALK-positive NSCLC.

Lorlatinib was specifically designed to penetrate the BBB and is a highly potent, selective, third-generation macrocyclic inhibitor of ALK and ROS1 with broad ALK mutational coverage [13]. Using radiolabeling and positron emission tomography imaging, lorlatinib demonstrated high BBB permeability and rapid brain uptake in animals [14, 15]. Lorlatinib has also shown antitumor activity in ALK-positive intracranial tumor models [16]. The high CNS penetration of lorlatinib noted in preclinical studies was confirmed in the clinic where the mean ratio of cerebrospinal fluid (CSF)/plasma (unbound) was 0.75 in four patients, who had matched samples available, from the phase I portion of the ongoing phase I/II study (NCT01970865) [17]. This phase I/II study demonstrated robust overall and intracranial antitumor activity of lorlatinib in patients with ALK-positive NSCLC, most of whom had CNS metastases at baseline and experienced treatment failure with $\geq 1$ ALK TKI [17, 18]. On the basis of data from this phase I/II study, the US Food and Drug Administration granted lorlatinib accelerated approval status in November 2018 for the treatment of patients with ALK-positive metastatic NSCLC who had disease progression on crizotinib and $\geq 1$ other ALK TKI or who had disease progression on alectinib or ceritinib as the first ALK TKI received. In May 2019, the European Commission also approved lorlatinib for use in these patient populations.

To further assess the effect of brain penetration with lorlatinib in the clinic, we report an analysis of CNS and
non-CNS progression in patients with ALK-positive NSCLC previously treated with ALK TKIs from the phase II portion of the phase I/II study. We also present antitumor activity data in previously irradiated brain lesions with progression at baseline and in patients with leptomeningeal disease.

\section{Materials and Methods}

\subsection{Study Design and Participants}

The full methodology for this ongoing, open-label, singlearm, multicenter phase II trial has been published [18]. Eligible patients were aged $\geq 18$ years and had histologically or cytologically confirmed metastatic NSCLC with either $A L K$ or ROSI rearrangement. ALK positivity was determined locally on the basis of the US Food and Drug Administration-approved fluorescence in situ hybridization assay (Abbott Molecular, Abbott Park, IL, USA) or by immunohistochemistry (Ventana Medical Systems, Tucson, AZ, USA). An Eastern Cooperative Oncology Group performance status of $\leq 2$ and $\geq 1$ measurable target extracranial lesion according to Response Evaluation Criteria in Solid Tumors (RECIST), version 1.1, were also required. Patients with untreated or treated (including those controlled with stable or decreasing steroid use within the last 2 weeks) asymptomatic CNS metastases were permitted. CNS metastases may be newly diagnosed or be present as progressive disease after surgery, whole-brain radiotherapy, or stereotactic radiosurgery. Prior radiotherapy must have been completed within 2 weeks of study entry (whole-brain radiotherapy: $\leq 4$ weeks). Patients with leptomeningeal disease/carcinomatosis were allowed to enroll if the disease was visualized on magnetic resonance imaging (MRI) or if baseline CSF-positive cytology was available.

Patients were enrolled into expansion cohorts (EXP) by their ALK (EXP1-5) or ROS1 (EXP6) status and treatment history. In this analysis, we focused on previously treated ALK-positive patients who were enrolled into EXP2-5. Specific enrolment criteria for these ALK-positive cohorts were as follows: progression following previous crizotinib only (EXP2), progression following previous crizotinib and one or two regimens of chemotherapy given before or after crizotinib (EXP3A), progression following one previous second-generation ALK TKI with or without chemotherapy (EXP3B), and ALK-positive patients with disease progression following two (EXP4) or three (EXP5) previous ALK TKIs with or without chemotherapy.

Patients were administered lorlatinib orally at a dose of $100 \mathrm{mg}$ once daily until progression, unacceptable toxicity, death, or withdrawal. Treatment beyond progression was permitted if the patient was still experiencing clinical benefit per the investigator's discretion. 
All patients provided written, informed consent before participation. The institutional review board or independent ethics committee at each participating site approved the protocol, which complied with the International Ethical Guidelines for Biomedical Research Involving Human Subjects, Good Clinical Practice guidelines, the Declaration of Helsinki, and local laws.

\subsection{Assessments}

All patients underwent baseline tumor imaging by computed tomography and brain imaging by MRI. Computed tomography and MRI scans were to be taken every 6 weeks for the first 30 months and then every 12 weeks thereafter until progressive disease or the start of a new anticancer treatment. Response was assessed according to modified RECIST, version 1.1, which allowed for up to five CNS target lesions, as assessed by independent central radiology review (ICR).

Adverse events (AEs) associated with the CNS were analyzed. They consisted of preferred terms from the Medical Dictionary for Regulatory Activities System Organ Class (SOC) of psychiatric disorders and SOC of nervous system disorders. Peripheral neuropathy was excluded as it represented an AE associated with the peripheral nervous system, but not the CNS. These AEs were assessed at baseline, every subsequent visit, and $\geq 28$ days after the final lorlatinib administration, and were graded according to the National Cancer Institute Common Terminology Criteria for Adverse Events, version 4.03.

\subsection{Statistical Analysis}

Patients were analyzed for progressive disease events, categorized as either CNS or non-CNS progression, by ICR. Any new CNS lesions or progression of pre-existing CNS lesions versus baseline was considered a CNS progression, while any new lesion or progression of pre-existing lesions in areas outside the CNS was considered non-CNS progression. If both CNS and non-CNS progression were presented simultaneously as the first progressive event, patients were considered to have CNS progression as their first event. The probability of a first event being a CNS progression, non-CNS progression, or death was estimated by cumulative incidences using a competing risks approach in patients with or without baseline CNS metastases. EXP2 and EXP3A were pooled because the included patients had all been treated with crizotinib (first-generation ALK TKI) as their only prior ALK TKI. EXP3B, EXP4, and EXP5 were pooled because the included patients had all received $\geq 1$ prior second-generation ALK TKI.

In an unplanned subgroup analysis, intracranial response was derived based on irradiated brain lesions with progression at baseline and new brain lesions only.
Other efficacy and statistical methodology has been previously described [18]. The data cutoff for this analysis was 2 February 2018.

\section{Results}

\subsection{Patients}

Patients were enrolled between 15 September 2015, and 3 October 2016. Baseline characteristics of the overall phase II population (EXP1-6) have been previously reported [18]. In this analysis, we report data from the 198 patients with ALK-positive NSCLC who had received $\geq 1$ ALK TKI and received $\geq 1$ dose of lorlatinib (EXP2-5). Of these patients, 59 received crizotinib as their only prior ALK TKI (EXP2-3A) and 139 received $\geq 1$ prior second-generation ALK TKI (EXP3B-5). Baseline CNS metastases (measurable/non-measurable) were present in 37 patients $(62.7 \%)$ from EXP2-3A and in 94 patients $(67.6 \%)$ from EXP3B-5. Baseline characteristics of the subgroups analyzed are shown in Table 1 and were generally comparable. There were more Asian patients (51.1\%) and fewer White patients $(33.3 \%)$ in the EXP3B-5 subgroup without baseline CNS metastases compared with all other subgroups (27.0-31.8\% and 50.0-54.3\%, respectively). Among patients with baseline CNS metastases in EXP2-3A and EXP3B-5, respectively, eight (21.6\%) and 30 (31.9\%) had irradiated brain lesions with progression at baseline; the median number was 3.5 lesions (range 2-10) and 5.0 lesions (range 1-11) per patient. At the time of data cutoff, the median duration of follow-up for progression-free survival for EXP2-3A and EXP3B-5 was 18.2 months (95\% confidence interval (CI) 18.0-21.1 months) and 19.1 months (95\% CI 16.5-20.8 months), respectively.

\subsection{CNS Versus Non-CNS Progression}

Figure 1 shows the cumulative incidences for CNS progression, non-CNS progression, and death with lorlatinib in patients who had received prior crizotinib as their only ALK TKI (EXP2-3A). In patients with baseline CNS metastases $(n=37)$, the cumulative incidence rates (CIRs) of CNS and non-CNS progression were $16 \%$ and $11 \%$ at 6 months, respectively, and $22 \%$ and $22 \%$ at 12 months, respectively (Fig. 1a; Table 2). In patients without baseline CNS metastases $(n=22)$, the CIR of non-CNS progression was higher versus that for CNS progression at both 6 months (24\% vs. 9\%) and 12 months (43\% vs. 9\%; Fig. $1 \mathrm{~b}$ and Table 2).

In patients who had received $\geq 1$ prior second-generation ALK TKI (EXP3B-5) with baseline CNS metastases $(n=94)$, the CIR of non-CNS progression was higher 
Table 1 Baseline characteristics of the pooled subgroups for this analysis by baseline metastases

\begin{tabular}{|c|c|c|c|c|}
\hline \multirow[t]{2}{*}{ Characteristic } & \multicolumn{2}{|c|}{ Prior crizotinib $^{\mathrm{a}}(\mathrm{EXP} 2-3 \mathrm{~A} ; n=59)$} & \multicolumn{2}{|c|}{$\begin{array}{l}\text { At least one prior second-generation ALK TKI } \\
\text { (EXP3B-5; } n=139)\end{array}$} \\
\hline & $\begin{array}{l}\text { Baseline CNS metastases } \\
(n=37)^{\mathrm{b}}\end{array}$ & $\begin{array}{l}\text { No baseline CNS metastases } \\
(n=22)\end{array}$ & $\begin{array}{l}\text { Baseline CNS metastases } \\
(n=94)^{\mathrm{b}}\end{array}$ & $\begin{array}{l}\text { No baseline } \\
\text { CNS metastases } \\
(n=45)\end{array}$ \\
\hline \multicolumn{5}{|l|}{ Age, years } \\
\hline Median & 54.0 & 58.0 & 50.5 & 56.0 \\
\hline Range & $30-74$ & $37-85$ & $29-77$ & $33-83$ \\
\hline \multicolumn{5}{|l|}{ Sex, $n(\%)$} \\
\hline Male & $12(32.4)$ & $8(36.4)$ & $40(42.6)$ & $21(46.7)$ \\
\hline Female & $25(67.6)$ & $14(63.6)$ & 54 (57.4) & $24(53.3)$ \\
\hline \multicolumn{5}{|l|}{ Race, $n(\%)$} \\
\hline White & $20(54.1)$ & $11(50.0)$ & $51(54.3)$ & $15(33.3)$ \\
\hline Asian & $10(27.0)$ & $7(31.8)$ & $30(31.9)$ & $23(51.1)$ \\
\hline Black & 0 & 0 & 0 & $1(2.2)$ \\
\hline Other & $1(2.7)$ & $1(4.5)$ & $4(4.3)$ & $2(4.4)$ \\
\hline Not specified & $6(16.2)$ & $3(13.6)$ & $9(9.6)$ & $4(8.9)$ \\
\hline \multicolumn{5}{|c|}{ ECOG PS, $n(\%)$} \\
\hline 0 & $17(45.9)$ & $11(50.0)$ & $45(47.9)$ & $16(35.6)$ \\
\hline 1 & $20(54.1)$ & $10(45.5)$ & $44(46.8)$ & $28(62.2)$ \\
\hline 2 & 0 & $1(4.5)$ & $5(5.3)$ & $1(2.2)$ \\
\hline \multicolumn{5}{|c|}{ Irradiated brain lesions with progression at screening } \\
\hline$n^{\mathrm{c}}(\%)$ & $8(21.6)$ & & $30(31.9)$ & \\
\hline \multicolumn{5}{|c|}{ Number of lesions, } \\
\hline Median & 3.5 & & 5.0 & \\
\hline Range & $2-10$ & & $1-11$ & \\
\hline
\end{tabular}

$A L K$ anaplastic lymphoma kinase, CNS central nervous system, ECOG PS Eastern Cooperative Oncology Group performance status, EXP expansion cohort, TKI tyrosine kinase inhibitor

${ }^{a}$ With or without chemotherapy

${ }^{\mathrm{b}}$ Includes patients with measurable and/or non-measurable CNS lesions

${ }^{\mathrm{c}}$ Number of patients with irradiated brain lesions with progression at screening by independent central review

versus that for CNS progression at 6 months (25\% vs. $14 \%)$ and at 12 months (35\% vs. $23 \%$; Fig. 2a; Table 2). Patients without baseline CNS metastases $(n=45)$ also had a higher CIR of non-CNS progression versus that for CNS progression, with CIRs of $37 \%$ versus $12 \%$ at 6 months and $55 \%$ versus $12 \%$ at 12 months (Fig. 2b; Table 2).

Of all patients previously treated with $\geq 1$ prior secondgeneration ALK TKI, 121 of 139 received a second-generation ALK TKI as their last ALK TKI prior to receiving lorlatinib, with most having last received alectinib $(n=62)$ or ceritinib $(n=47)$. The curves of cumulative incidence for CNS and non-CNS progression were similar to those for the overall EXP3B-5 subgroups (Fig. 3). Similarly, the CIR of non-CNS progression was higher versus that for CNS progression in patients with or without baseline CNS metastases at 6 months (27\% vs. $15 \%$ and $38 \%$ vs. $11 \%$, respectively) and at 12 months (37\% vs. $23 \%$ and $53 \%$ vs. $11 \%$, respectively; Supplementary Table A.1).

\subsection{Intracranial Antitumor Activity}

Baseline measurable CNS metastases were present in 24 (64.9\%) out of 37 patients in EXP2-3A and 57 (60.6\%) out of 94 patients in EXP3B-5. In EXP2-3A, intracranial responses were observed in $21(87.5 \%, 95 \%$ CI 67.6-97.3) of 24 patients (Table 3). Median duration of response was not reached (95\% CI 15.2 months-not estimable). Of the 57 patients in EXP3B-5, 31 (54.4\%; 95\% CI 40.7-67.6) achieved an intracranial response and the median duration of response was 12.4 months (95\% CI 5.8-not estimable). 
Fig. 1 Cumulative incidence of CNS progression, non-CNS progression, and death with lorlatinib in patients with prior crizotinib* (EXP2-3A). a Patients with baseline CNS metastases and $\mathbf{b}$ patients without baseline CNS metastases. *With or without chemotherapy. $C N S$ central nervous system, EXP expansion cohort, $P D$ progressive disease
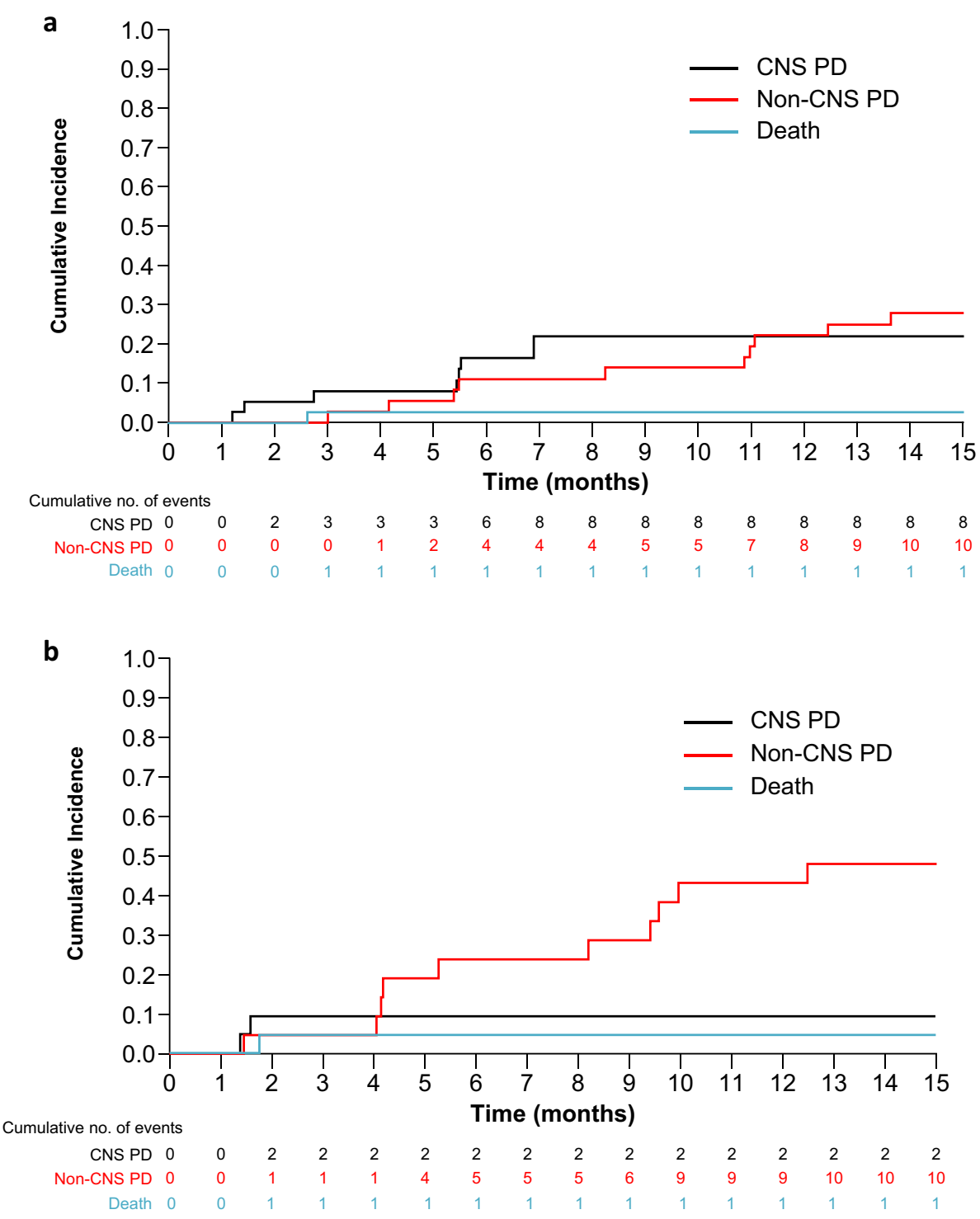

Table 2 Cumulative incidence probabilities for CNS progression, non-CNS progression, and death at 6 and 12 months

\begin{tabular}{|c|c|c|c|c|}
\hline & \multicolumn{2}{|c|}{ Prior crizotinib $^{\mathrm{a}}(\mathrm{EXP} 2-3 \mathrm{~A} ; n=59)$} & \multicolumn{2}{|c|}{$\begin{array}{l}\text { At least one prior second-generation ALK TKI } \\
(\text { EXP3B-5; } n=139)\end{array}$} \\
\hline & $\begin{array}{l}\text { Baseline CNS metastases } \\
(n=37)\end{array}$ & $\begin{array}{l}\text { No baseline CNS metastases } \\
(n=22)\end{array}$ & $\begin{array}{l}\text { Baseline CNS metastases } \\
(n=94)\end{array}$ & $\begin{array}{l}\text { No baseline CNS } \\
\text { metastases }(n=45)\end{array}$ \\
\hline \multicolumn{5}{|c|}{ CNS progression } \\
\hline 6 months & $0.16(0.07-0.30)$ & $0.09(0.02-0.25)$ & $0.14(0.07-0.22)$ & $0.12(0.04-0.24)$ \\
\hline 12 months & $0.22(0.10-0.36)$ & $0.09(0.02-0.25)$ & $0.23(0.15-0.33)$ & $0.12(0.04-0.24)$ \\
\hline \multicolumn{5}{|c|}{ Non-CNS progression } \\
\hline 6 months & $0.11(0.04-0.24)$ & $0.24(0.09-0.43)$ & $0.25(0.17-0.35)$ & $0.37(0.22-0.51)$ \\
\hline 12 months & $0.22(0.10-0.37)$ & $0.43(0.22-0.62)$ & $0.35(0.25-0.45)$ & $0.55(0.38-0.69)$ \\
\hline \multicolumn{5}{|l|}{ Death } \\
\hline 6 months & $0.03(0.00-0.12)$ & $0.05(0.00-0.19)$ & $0.07(0.03-0.13)$ & $0.05(0.01-0.15)$ \\
\hline 12 months & $0.03(0.00-0.12)$ & $0.05(0.00-0.19)$ & $0.07(0.03-0.13)$ & $0.08(0.02-0.19)$ \\
\hline
\end{tabular}

Data are given as cumulative incidence probability (95\% confidence interval)

$A L K$ anaplastic lymphoma kinase, $C N S$ central nervous system, EXP expansion cohort, TKI tyrosine kinase inhibitor

${ }^{\mathrm{a}}$ With or without chemotherapy 
Fig. 2 Cumulative incidence of CNS progression, non-CNS progression, and death with lorlatinib in patients with at least one prior second-generation ALK TKI* (EXP3B-5). a Patients with baseline CNS metastases and $\mathbf{b}$ patients without baseline CNS metastases. *With or without chemotherapy. $A L K$ anaplastic lymphoma kinase, $C N S$ central nervous system, EXP expansion cohort, $P D$ progressive disease, $T K I$ tyrosine kinase inhibitor
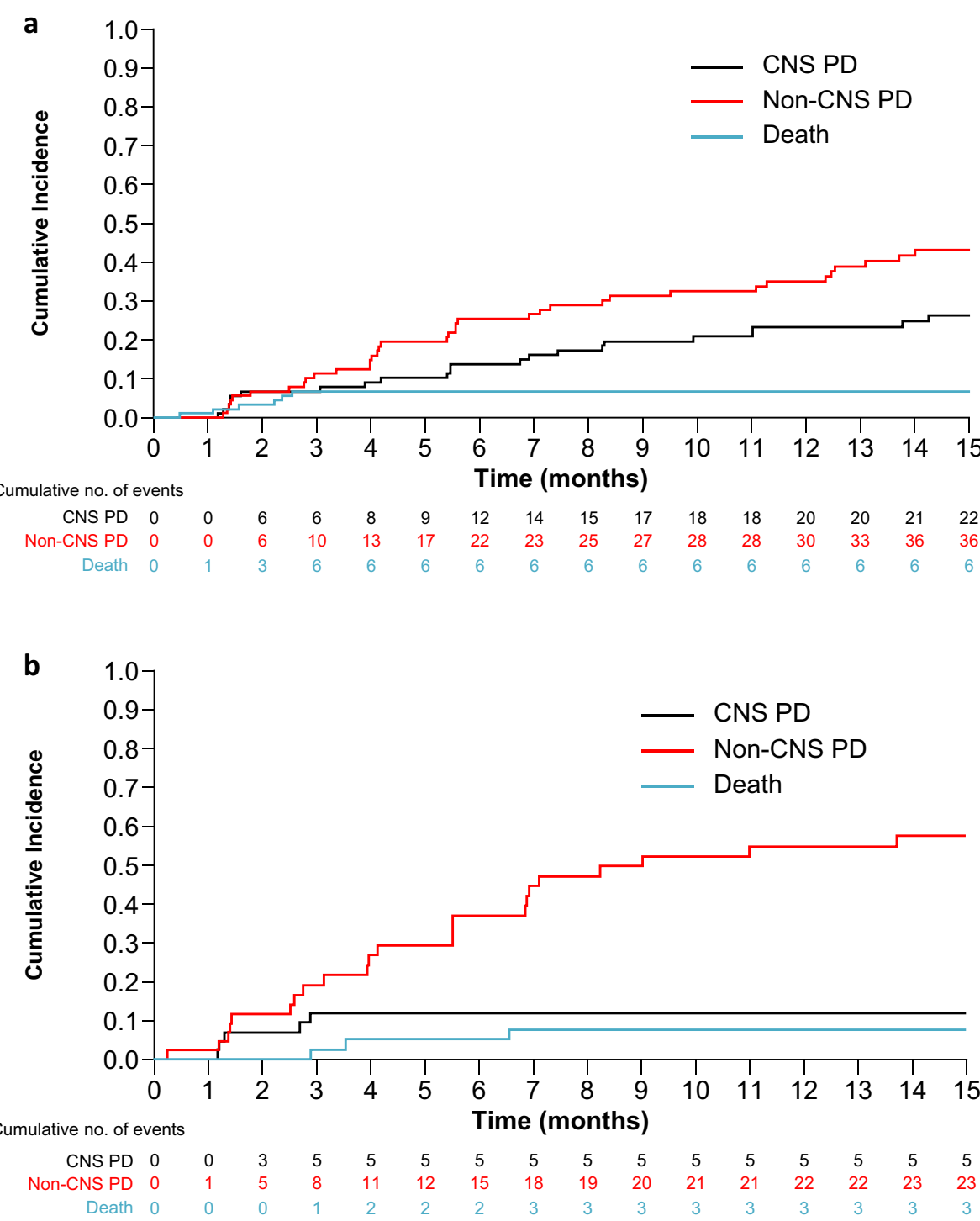

\subsection{Antitumor Activity in Irradiated Brain Lesions with Progression at Baseline}

In EXP2-3A, intracranial responses in irradiated brain lesions with progression at baseline were observed in four (50.0\%; 95\% CI 15.7-84.3) of eight patients and median duration of intracranial response was not reached (95\% CI 2.8-not estimable; Fig. 4a; Supplementary Table A.2). Of 30 patients in EXP3B-5, 12 (40.0\%; 95\% CI 22.7-59.4) achieved an intracranial response in irradiated brain lesions with progression at baseline and median duration of intracranial response was 12.4 months (95\% CI 11.1-not estimable; Fig. 4b; Supplementary Table A.2). Best responses of stable disease in irradiated brain lesions with progression at baseline were observed in three (37.5\%) and ten (33.3\%) patients, respectively, with some lasting $>6$ months (Fig. 4; Supplementary Table A.2).

\subsection{Leptomeningeal Disease/Carcinomatosis}

Lorlatinib was also active in the two ALK-positive patients with leptomeningeal disease at baseline. One patient had overall and intracranial responses of complete response, and had not progressed at the time of analysis, with an overall time to progression of 21.9 months (in follow-up for progression). The second patient achieved overall and intracranial responses of partial response; the overall time to progression was 11 months.

\subsection{Safety}

The safety profile of lorlatinib based on the overall phase II population has been previously reported, with CNS effects (e.g., cognitive and mood effects) among the 
Fig. 3 Cumulative incidence of CNS progression, non-CNS progression, and death with lorlatinib in patients with a second-generation ALK TKI* as their last prior TKI. a Patients with baseline CNS metastases and $\mathbf{b}$ patients without baseline CNS metastases. *Secondgeneration ALK TKIs included: alectinib $(n=62)$, ceritinib $(n=47)$, brigatinib $(n=8)$; other TKI (ensartinib or entrectinib) $(n=4) . A L K$ anaplastic lymphoma kinase, CNS central nervous system, EXP expansion cohort, $P D$ progressive disease, $T K I$ tyrosine kinase inhibitor
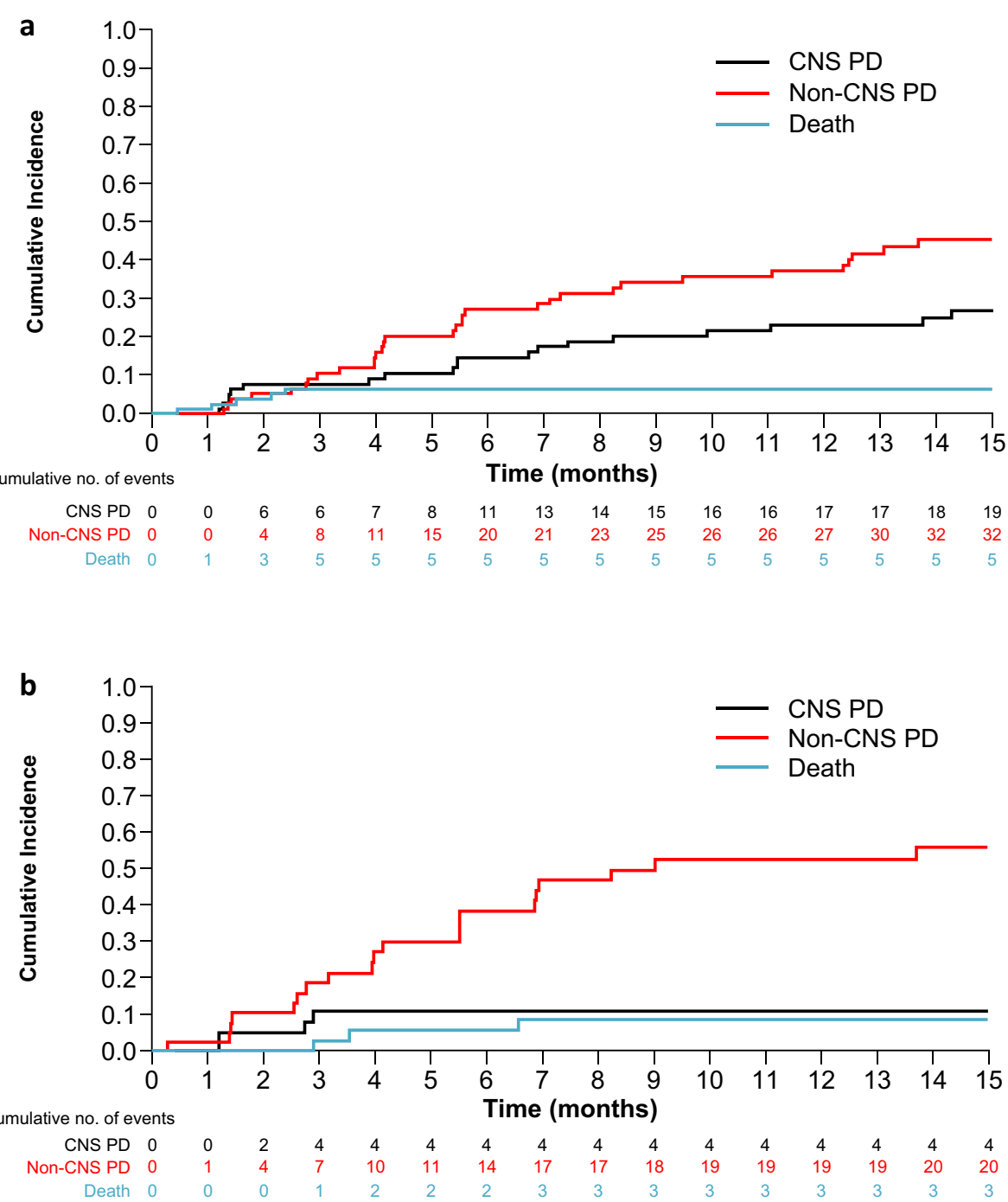

Table 3 Intracranial antitumor activity by independent central review in patients with $\geq 1$ measurable CNS lesion at baseline

Prior crizotinib $^{\mathrm{a}}(\mathrm{EXP} 2-3 \mathrm{~A} ; n=24) \quad$ At least one prior second-generation ALK TKI ${ }^{\mathrm{a}}$ (EXP3B-5; $n=57$ )

Best overall intracranial response, $n(\%)$

$\begin{array}{lll}\text { Complete response } & 6(25.0) & 12(21.1) \\ \text { Partial response } & 15(62.5) & 19(33.3) \\ \text { Stable disease } & 3(12.5) & 17(29.8) \\ \text { Objective progression } & 0 & 6(10.5) \\ \text { Indeterminate } & 0 & 3(5.3) \\ \text { Objective response rate, } n(\%) & 21(87.5) & 31(54.4) \\ 95 \% \text { CI } & 67.6-97.3 & 40.7-67.6\end{array}$

Duration of intracranial response, months

Median

NR

12.4

95\% CI

15.2-NE

5.8-NE

$N E$ not evaluable, $N R$ not reached

${ }^{\mathrm{a}} \mathrm{With}$ or without chemotherapy 
Fig. 4 Percentage change from baseline in tumor size of previously irradiated brain lesions in progression at baseline*. a Patients with prior crizotinib ${ }^{\dagger}$ (EXP2-3A) and b patients with at least one prior second-generation ALK TKI ${ }^{\dagger}$ (EXP3B-5). *Based on derived independent central review. ${ }^{\dagger}$ With or without chemotherapy. $A L K$ anaplastic lymphoma kinase, EXP expansion cohort, $P D$ progressive disease, $T K I$ tyrosine kinase inhibitor
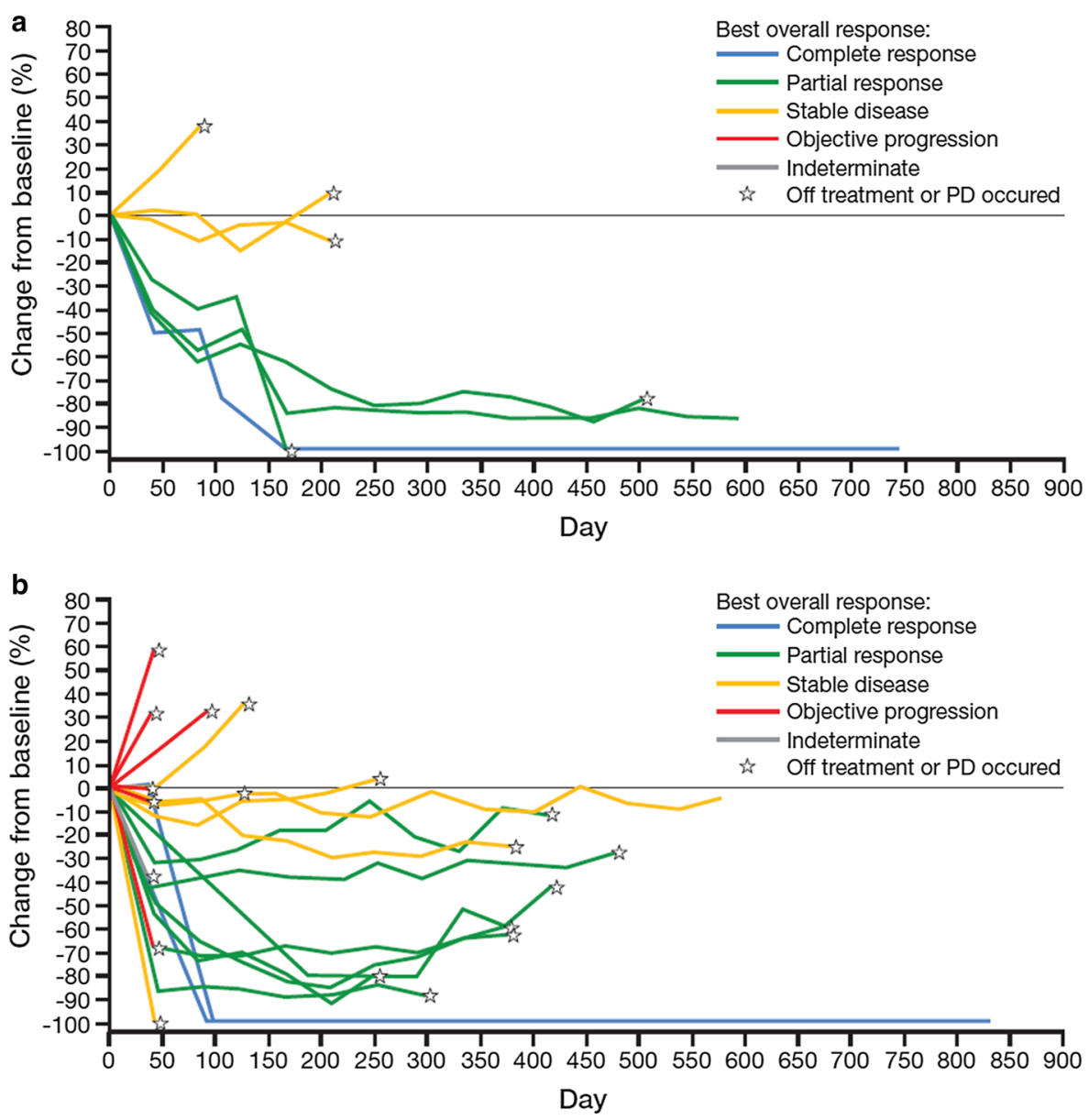

most common treatment-related AEs [18]. Treatmentrelated AEs associated with the CNS (any grade) were reported in 71 of 131 patients $(54.2 \%)$ with baseline CNS metastases and 33 of 67 patients $(49.3 \%)$ without baseline CNS metastases (Supplementary Table A.3). Grade 3-4 treatment-related AEs associated with the CNS occurred in $2.3 \%$ and $7.5 \%$ of patients with and without baseline CNS metastases, respectively. Cognitive effects $(26.0 \%$ and $19.4 \%$, respectively) and mood effects (16.8\% and $16.4 \%$, respectively) were the most frequently reported treatment-related CNS AEs in patients with or without baseline CNS metastases.

\section{Discussion}

Despite impressive initial responses among patients with ALK-positive advanced NSCLC following treatment with the first-generation ALK TKI crizotinib and with secondgeneration ALK TKIs, including ceritinib, alectinib, and brigatinib, CNS progression remains a clinically significant problem $[5,7,8,19]$. Thus, there remains a need for effective management of CNS metastases in ALK-positive NSCLC. Our findings indicate that lorlatinib has robust CNS activity in patients with previously treated ALKpositive NSCLC with or without baseline CNS metastases whose disease progressed on crizotinib and/or secondgeneration ALK TKIs.

Among patients with baseline CNS metastases previously treated with crizotinib or second-generation TKIs, the CIR of CNS progression at 12 months was relatively low (22-23\%), and the cumulative incidence curves indicate that the probability of extracranial progression was generally higher than intracranial progression, indicating that lorlatinib is highly active against CNS metastases. Furthermore, as evident by the relatively small increases in the CIR between 6 and 12 months, protection against progression in the CNS persisted over time with lorlatinib treatment, suggesting that this benefit to the CNS is durable. A similar analysis with alectinib in crizotinibrefractory patients reported a consistently higher CIR of CNS progression than non-CNS progression in patients with baseline CNS metastases [20]. In patients without baseline CNS metastases in our study, the higher CIR for 
non-CNS progression than for CNS progression in both patient groups indicates that lorlatinib may also prevent metastatic spread to the brain in ALK-positive NSCLC. This protective effect in patients without baseline CNS disease was maintained over time, as evidenced by the unchanged CIR of CNS progression (9\% for EXP2-3A and $12 \%$ for EXP3B-5) between 6 and 12 months in both groups. Although these findings should be interpreted with caution, given the small patient numbers in some subgroups and the exploratory post hoc nature of the analysis, these data further support the substantial intracranial antitumor activity seen in patients treated with previous crizotinib only or previous second-generation ALK TKIs in this phase II study. Lorlatinib also showed clinically meaningful benefit in previously irradiated brain lesions that were in progression at baseline, a subset of metastases for which treatment options are limited. Local reirradiation or whole-brain radiotherapy may be considered for patients with these metastases; however, neurocognitive impairment and decreased quality of life remain significant issues with such treatments [21,22]. Together, our findings indicate that the robust CNS activity of lorlatinib may assuage the need for additional treatment with local CNS-directed therapies. Thus, lorlatinib represents a highly effective treatment option for patients who have CNS progression on ALK TKIs, including brain-penetrant, second-generation TKIs.

The generally lower CIRs of CNS progression than nonCNS progression reported here, together with previously reported efficacy results [18], may suggest that lorlatinib has more durable activity in the CNS than in extracranial sites. A potential reason for this difference might be that CNS lesions have been exposed to fewer therapies at baseline due to the BBB attenuating CNS exposure to prior treatments, such as ALK TKIs and chemotherapy, to varying extents. An analysis of lorlatinib-resistant biopsies found an accumulation of $A L K$ resistance mutations through sequential ALK TKIs, suggesting that less exposure to ALK TKIs may prevent the emergence of mutations that confer resistance to lorlatinib [23]. Thus, it is tempting to speculate that there would be less mutational heterogeneity in CNS lesions than non-CNS lesions, with fewer resistance mutations having likely developed. Additionally, tumor microenvironments at specific metastatic sites (e.g., brain, lung, and liver) can be widely diverse and have been shown to influence response to anti-cancer treatments $[24,25]$.

Leptomeningeal carcinomatosis is associated with poor prognosis and, thus, is listed in the exclusion criteria for the majority of NSCLC trials [26]. In our study, durable overall and intracranial responses were observed in both patients who presented with leptomeningeal involvement at baseline. Notwithstanding the small number of patients, these data suggest lorlatinib may have activity against leptomeningeal disease, which could potentially be explained by its high CNS permeability as demonstrated in preclinical studies [14, 15]. Other brain-penetrant ALK TKIs, alectinib and ceritinib, have shown analogous activity in case reports of leptomeningeal carcinomatosis, further substantiating this hypothesis $[27,28]$.

AEs associated with the CNS reported with lorlatinib were generally mild to moderate in severity and were comparable between patients with or without baseline CNS metastases. Further details on CNS effects associated with lorlatinib treatment (i.e., changes in cognitive function, mood, and speech, and comprehensive guidance on the management of the unique $\mathrm{AE}$ profile) have been published [29].

Overall, the results of this analysis show that lorlatinib is active in the treatment and prevention of CNS metastases in patients with ALK-positive NSCLC with or without baseline CNS metastases whose disease progressed on crizotinib and/or second-generation ALK TKIs.

Acknowledgements Medical writing support was provided by Jade Drummond and Brian Szente of inScience Communications, Springer Healthcare (Chester, UK and Philadelphia, PA, USA), and was funded by Pfizer Inc.

Author Contributions All authors made substantial contributions to the conception and design, or analysis and interpretation of data, and to the drafting of the manuscript or revising it critically for important intellectual content. Additionally, all authors provided final approval of the version to be submitted.

Data Sharing Statement Upon request, and subject to certain criteria, conditions, and exceptions (see https://www.pfizer.com/scien ce/clinical-trials/trial-data-and-results for more information), Pfizer will provide access to individual deidentified participant data from Pfizer-sponsored global interventional clinical studies conducted for medicines, vaccines, and medical devices (1) for indications that have been approved in the US and/or EU or (2) in programs that have been terminated (ie, development for all indications has been discontinued). Pfizer will also consider requests for the protocol, data dictionary, and statistical analysis plan. Data may be requested from Pfizer trials 24 months after study completion. The deidentified participant data will be made available to researchers whose proposals meet the research criteria and other conditions, and for which an exception does not apply, via a secure portal. To gain access, data requestors must enter into a data access agreement with Pfizer.

\section{Compliance with Ethical Standards}

Funding This study was sponsored by Pfizer Inc.

Conflict of interest TMB has received fees for consulting/advisory board roles for Guardant Health, Ignyta, Loxo, Moderna Therapeutics, and Pfizer Inc. ATS has received fees for consulting/advisory board roles from Ariad/Takeda, Bayer, Blueprint Medicines, Chugai, Daiichi Sankyo, EMD Serono, Genentech, Ignyta, KSQ Therapeutics, Loxo, Natera, Novartis, Pfizer, Roche, Taiho, and TP Therapeutics, and honoraria from Foundation Medicine, Guardant, Novartis, Pfizer, 
and Roche. AN has received fees for consult/advisory board roles from Boehringer Ingelheim, Roche, Pfizer, Bristol-Myers Squibb, Oryzon Genomics and travel expenses from Pfizer and Boehringer Ingelheim. MLJ has nothing to disclose. JFG has received fees for consulting/ advisory board roles from Bristol-Myers Squibb, Genentech/Roche, Novartis, Loxo, Theravance, Clovis, Merck, Boehringer Ingelheim, and Incyte. HT, GP, YKP, and AA own stock in and are employees of Pfizer. EF has received fees for consulting/advisory board roles for Celgene, Eli Lilly, Guardant Health, and Takeda, and has served as a consultant and on the speakers' bureau for AstraZeneca, Boehringer Ingelheim, Bristol-Myers Squibb, Merck Sharp \& Dohme, Novartis, Pfizer, and Roche.

Open Access This article is licensed under a Creative Commons Attribution-NonCommercial 4.0 International License, which permits any non-commercial use, sharing, adaptation, distribution and reproduction in any medium or format, as long as you give appropriate credit to the original author(s) and the source, provide a link to the Creative Commons licence, and indicate if changes were made. The images or other third party material in this article are included in the article's Creative Commons licence, unless indicated otherwise in a credit line to the material. If material is not included in the article's Creative Commons licence and your intended use is not permitted by statutory regulation or exceeds the permitted use, you will need to obtain permission directly from the copyright holder.To view a copy of this licence, visit http://creativecommons.org/licenses/by-nc/4.0/.

\section{References}

1. Johung KL, Yeh N, Desai NB, Williams TM, Lautenschlaeger $\mathrm{T}$, Arvold ND, et al. Extended survival and prognostic factors for patients with ALK-rearranged non-small-cell lung cancer and brain metastasis. J Clin Oncol. 2016;34(2):123-9. https://doi. org/10.1200/JCO.2015.62.0138

2. Berger LA, Riesenberg H, Bokemeyer C, Atanackovic D. CNS metastases in non-small-cell lung cancer: current role of EGFR-TKI therapy and future perspectives. Lung Cancer. 2013;80(3):242-8. https://doi.org/10.1016/j.lungcan.2013.02.004.

3. Guerin A, Sasane M, Zhang J, Culver KW, Dea K, Nitulescu R, et al. Brain metastases in patients with ALK+ non-small cell lung cancer: clinical symptoms, treatment patterns and economic burden. J Med Econ. 2015;18(4):312-22. https://doi. org/10.3111/13696998.2014.1003644.

4. Yoshida T, Oya Y, Tanaka K, Shimizu J, Horio Y, Kuroda H, et al. Clinical impact of crizotinib on central nervous system progression in ALK-positive non-small lung cancer. Lung Cancer. 2016;97:43-7. https://doi.org/10.1016/j.lungcan.2016.04.006.

5. Solomon BJ, Mok T, Kim DW, Wu YL, Nakagawa K, Mekhail T, et al. First-line crizotinib versus chemotherapy in ALK-positive lung cancer. N Engl J Med. 2014;371(23):2167-77. https://doi. org/10.1056/NEJMoa1408440.

6. Kim DW, Tiseo M, Ahn MJ, Reckamp KL, Hansen KH, Kim $\mathrm{SW}$, et al. Brigatinib in patients with crizotinib-refractory anaplastic lymphoma kinase-positive non-small-cell lung cancer: a randomized, multicenter phase II trial. J Clin Oncol. 2017;35(22):2490-8. https://doi.org/10.1200/JCO.2016.71.5904.

7. Peters S, Camidge DR, Shaw AT, Gadgeel S, Ahn JS, Kim DW, et al. Alectinib versus crizotinib in untreated ALK-positive nonsmall-cell lung cancer. N Engl J Med. 2017;377(9):829-38. https://doi.org/10.1056/NEJMoa1704795.

8. Soria JC, Tan DSW, Chiari R, Wu YL, Paz-Ares L, Wolf J, et al. First-line ceritinib versus platinum-based chemotherapy in advanced ALK-rearranged non-small-cell lung cancer
(ASCEND-4): a randomised, open-label, phase 3 study. Lancet. 2017;389(10072):917-29. https://doi.org/10.1016/S0140 $-6736(17) 30123-X$.

9. Costa DB, Shaw AT, Ou SH, Solomon BJ, Riely GJ, Ahn MJ, et al. Clinical experience with crizotinib in patients with advanced ALK-rearranged non-small-cell lung cancer and brain metastases. J Clin Oncol. 2015;33(17):1881-8. https:// doi.org/10.1200/JCO.2014.59.0539.

10. Katayama R, Shaw AT, Khan TM, Mino-Kenudson M, Solomon BJ, Halmos B, et al. Mechanisms of acquired crizotinib resistance in ALK-rearranged lung cancers. Sci Transl Med. 2012;4(120):120ra117. https://doi.org/10.1126/scitranslm ed.3003316.

11. Solomon BJ, Cappuzzo F, Felip E, Blackhall FH, Costa DB, Kim DW, et al. Intracranial efficacy of crizotinib versus chemotherapy in patients with advanced ALK-positive non-smallcell lung cancer: results from PROFILE 1014. J Clin Oncol. 2016;34(24):2858-65. https://doi.org/10.1200/JCO.2015.63.5888.

12. Costa DB, Kobayashi S, Pandya SS, Yeo WL, Shen Z, Tan W, et al. CSF concentration of the anaplastic lymphoma kinase inhibitor crizotinib. J Clin Oncol. 2011;29(15):e443-5. https:// doi.org/10.1200/JCO.2010.34.1313.

13. Johnson TW, Richardson PF, Bailey S, Brooun A, Burke BJ, Collins MR, et al. Discovery of (10R)-7-amino-12-fluoro-2,10,16trimethyl-15-oxo-10,15,16,17-tetrahydro- $2 \mathrm{H}-8,4$-(m etheno) pyrazolo[4,3-h][2,5,11]-benzoxadiazacyclotetradecine-3-carbonitrile (PF-06463922), a macrocyclic inhibitor of anaplastic lymphoma kinase (ALK) and c-ros oncogene 1 (ROS1) with preclinical brain exposure and broad-spectrum potency against ALK-resistant mutations. J Med Chem. 2014;57(11):4720-44. https://doi.org/10.1021/jm500261q.

14. Collier TL, Maresca KP, Normandin MD, Richardson P, McCarthy TJ, Liang SH, et al. Brain penetration of the ROS1/ ALK inhibitor lorlatinib confirmed by PET. Mol Imaging. 2017;16:1536012117736669. https://doi.org/10.1177/1536012117 736669.

15. Collier TL, Normandin MD, Stephenson NA, Livni E, Liang SH, Wooten DW, et al. Synthesis and preliminary PET imaging of (11)C and (18)F isotopologues of the ROS1/ALK inhibitor lorlatinib. Nat Commun. 2017;8:15761. https://doi.org/10.1038/ncomm s15761.

16. Zou HY, Friboulet L, Kodack DP, Engstrom LD, Li Q, West M, et al. PF-06463922, an ALK/ROS1 inhibitor, overcomes resistance to first and second generation ALK inhibitors in preclinical models. Cancer Cell. 2015;28(1):70-81. https://doi.org/10.1016/j. ccell.2015.05.010.

17. Shaw AT, Felip E, Bauer TM, Besse B, Navarro A, Postel-Vinay S, et al. Lorlatinib in non-small-cell lung cancer with ALK or ROS1 rearrangement: an international, multicentre, open-label, singlearm first-in-man phase 1 trial. Lancet Oncol. 2017;18(12):1590-9. https://doi.org/10.1016/S1470-2045(17)30680-0.

18. Solomon BJ, Besse B, Bauer TM, Felip E, Soo RA, Camidge $\mathrm{DR}$, et al. Lorlatinib in patients with ALK-positive non-smallcell lung cancer: results from a global phase 2 study. Lancet Oncol. 2018;19(12):1654-67. https://doi.org/10.1016/S1470 -2045(18)30649-1.

19. Camidge DR, Kim HR, Ahn MJ, Yang JC, Han JY, Lee JS, et al. Brigatinib versus crizotinib in ALK-positive non-small-cell lung cancer. N Engl J Med. 2018;379(21):2027-39. https://doi. org/10.1056/NEJMoa1810171.

20. Gadgeel S, Shaw AT, Barlesi F, Crino L, Yang JC, Dingemans $\mathrm{AC}$, et al. Cumulative incidence rates for CNS and non-CNS progression in two phase II studies of alectinib in ALK-positive NSCLC. Br J Cancer. 2018;118(1):38-42. https://doi.org/10.1038/ bjc.2017.395. 
21. Soffietti R, Kocher M, Abacioglu UM, Villa S, Fauchon F, Baumert BG, et al. A European Organisation for Research and Treatment of Cancer phase III trial of adjuvant whole-brain radiotherapy versus observation in patients with one to three brain metastases from solid tumors after surgical resection or radiosurgery: quality-of-life results. J Clin Oncol. 2013;31(1):65-72. https ://doi.org/10.1200/JCO.2011.41.0639.

22. Brown PD, Jaeckle K, Ballman KV, Farace E, Cerhan JH, Anderson SK, et al. Effect of radiosurgery alone vs radiosurgery with whole brain radiation therapy on cognitive function in patients with 1 to 3 brain metastases: a randomized clinical trial. JAMA. 2016;316(4):401-9. https://doi.org/10.1001/jama.2016.9839.

23. Yoda S, Lin JJ, Lawrence MS, Burke BJ, Friboulet L, Langenbucher A, et al. Sequential ALK inhibitors can select for lorlatinibresistant compound ALK mutations in ALK-positive lung cancer. Cancer Discov. 2018;8(6):714-29. https://doi.org/10.1158/21598290.CD-17-1256.

24. Alsaggar M, Yao Q, Cai H, Liu D. Differential growth and responsiveness to cancer therapy of tumor cells in different environments. Clin Exp Metastasis. 2016;33(2):115-24. https://doi. org/10.1007/s10585-015-9761-y.

25. Devaud C, Westwood JA, John LB, Flynn JK, Paquet-Fifield S, Duong CP, et al. Tissues in different anatomical sites can sculpt and vary the tumor microenvironment to affect responses to therapy. Mol Ther. 2014;22(1):18-27. https://doi.org/10.1038/ mt.2013.219.

26. Leal T, Chang JE, Mehta M, Robins HI. Leptomeningeal metastasis: challenges in diagnosis and treatment. Curr Cancer Ther Rev. 2011;7(4):319-27. https://doi.org/10.2174/157339411797642597.

27. Arrondeau J, Ammari S, Besse B, Soria JC. LDK378 compassionate use for treating carcinomatous meningitis in an ALK translocated non-small-cell lung cancer. J Throac Oncol. 2014;9(8):e623. https://doi.org/10.1097/JTO.0000000000000174.

28. Ou SH, Sommers KR, Azada MC, Garon EB. Alectinib induces a durable ( $>15$ months) complete response in an ALK-positive non-small cell lung cancer patient who progressed on crizotinib with diffuse leptomeningeal carcinomatosis. Oncologist. 2015;20(2):224-6. https://doi.org/10.1634/theoncolog ist.2014-0309.

29. Bauer TM, Felip E, Solomon BJ, Thurm H, Peltz G, Chioda MD, et al. Clinical management of adverse events associated with lorlatinib. Oncologist. 2019;24(8):1103-10. https://doi.org/10.1634/ theoncologist.2018-0380. 